\title{
Surveillance after Curative Resection of Colorectal Cancer
}

\author{
Adena Scheer, M.D. ${ }^{1}$ and Rebecca Ann C. Auer, M.D., M.Sc. ${ }^{2}$
}

Surgical resection is the primary treatment modality for patients with localized colorectal cancer, but unfortunately one-third to one-half of these patients will develop a recurrence. If detected early, recurrent disease may be amenable to surgical resection and this provides the rationale for a follow-up strategy in patients with resected colorectal cancer. Despite eight published randomized controlled trials and six published systematic reviews evaluating different follow-up strategies, there is still no consensus as to the appropriateness of follow-up in colorectal cancer patients. In the present article the authors explore the reasons behind the controversy and the arguments used to support each side. They outline the current published guidelines and the data to support these recommendations, including the use of carcinoembryonic antigen (CEA) levels, liver imaging, and colonoscopy. Finally, they speculate on the future developments that may impact on this debate.

KEYWORDS: Colorectal neoplasm, postoperative surveillance, colorectal surgery

Objectives: On completion of this article the reader should be able to summarize the current recommendation for surveillance after curative resection of colorectal cancer and the evidence supporting these recommendations.

Colorectal cancer is the third most common cancer diagnosed in North America and approximately two-thirds of patients will undergo surgical resection, with or without adjuvant chemotherapy for curative intent. Unfortunately, 30 to $50 \%$ of patients will develop recurrent disease with greater than $90 \%$ of recurrences occurring in the first 5 years following surgery. ${ }^{1}$ Recurrent and metastatic disease or a second primary colon cancer, if detected early, may be amenable to a potentially curative surgical resection. This provides the rationale for a follow-up strategy in patients with resected colorectal cancer.

Despite a fairly extensive body of literature evaluating the benefit of various colorectal cancer follow-up strategies, there remains significant debate surrounding this topic.

To date, there have been eight published randomized controlled trials ${ }^{2-9}$ and six published systematic reviews ${ }^{10-15}$ of randomized trials evaluating different follow-up strategies. Despite this wealth of high-quality clinical trials there is still no consensus as to the appropriateness of follow-up in colorectal cancer patients, and very little agreement on the modalities that should be employed or the frequency with which they should be used. A consensus for colorectal cancer follow-up would have far reaching implications because $\sim 230,000$ patients who undergo curative colorectal cancer resections each year are
${ }^{1}$ Department of Surgery, University of Ottawa, Ottawa, Ontario, Canada; ${ }^{2}$ Surgical Oncology and Colorectal Surgery, Ottawa Health Research Institute, University of Ottawa, Ottawa, Ontario, Canada.

Address for correspondence and reprint requests: Rebecca Ann C. Auer, M.D., Surgical Oncology and Colorectal Surgery, Ottawa Health Research Institute, University of Ottawa, Ottawa HospitalGeneral Campus, 501 Smyth Rd., CCW 1617, Ottawa, ON, K1H
8L6 Canada (e-mail: rauer@ohri.ca).

Colorectal Cancer; Guest Editor, Robin P. Boushey, M.D., Ph.D.

Clin Colon Rectal Surg 2009;22:242-250. Copyright (C) 2009 by Thieme Medical Publishers, Inc., 333 Seventh Avenue, New York, NY 10001, USA. Tel: +1(212) 584-4662.

DOI 10.1055/s-0029-1242464. ISSN 1531-0043. 
candidates for follow-up in the United States, Canada, and Europe. ${ }^{16}$

Here we will explore the reasons behind the controversy and the arguments used to support each side. We will outline the current published guidelines by various national and international societies and the data to support these recommendations, including the use of carcinoembryonic antigen (CEA) levels, liver imaging, and colonoscopy. Finally, we speculate on the future developments that may impact on this debate, including currently open clinical trials evaluating the role of colorectal cancer follow-up in the setting of contemporary hepatobiliary surgery and chemotherapy, and newer screening strategies, such as 18-fluorodeoxyuridine positron emission tomography $\left({ }^{18} \mathrm{FDG}-\mathrm{PET}\right)$.

\section{RATIONALE FOR COLORECTAL CANCER FOLLOW-UP}

The principal aim for a follow-up program after completion of cancer therapy is to improve survival. This premise requires that effective treatment be available for patients who experience recurrence, but that the effectiveness of the treatment is superior when the recurrence is detected prior to the development of symptoms. In the case of colorectal cancer, the treatment is surgery for resectable recurrences and new primary tumors. Longterm survival data has been published for complete resection of local recurrences, regional recurrences (retroperitoneal and mesenteric) and metastatic recurrences, including the liver and lung. Several studies have also demonstrated that asymptomatic recurrences of colorectal cancer are more amenable to an R0 (margin negative) surgical resection. ${ }^{2,5,7}$

\section{RANDOMIZED CONTROLLED DATA}

Eight randomized controlled trials have enrolled 2,923 patients with colorectal cancer undergoing curative resection from 1983 to $20044^{2,4-9}$ In each study, an intensive follow-up strategy was compared with either a control ${ }^{2,5,8,9}$ or minimal ${ }^{3,4,6,7}$ follow-up strategy with a wide variation in the follow-up intensities and modalities used between the various trials (Table 1). The target population of each study was patients with colorectal cancer (Dukes stage A, B, and C) treated surgically with curative intent. The primary endpoint was overall survival at 5 years in seven trials ${ }^{2-9}$ and disease-specific survival in one trial. ${ }^{3}$ Other outcome measures included frequency and time to recurrence, the number of asymptomatic recurrences and the number of curative surgeries performed for recurrence. Two of the eight randomized controlled trials met their primary endpoint and demonstrated that "intensive" postoperative surveillance improved overall survival. ${ }^{5,7}$ Both of these studies included CEA and liver imaging in the intensive arm. However, although the study by Secco et $\mathrm{al}^{7}$ had a truly minimal follow-up strategy in the control arm, the study by Pietra et $\mathrm{al}^{5}$ had CEA and liver ultrasound in the control arm, albeit less frequently. Though none of the studies demonstrated a difference in the total number of recurrences detected between the intensive and control groups, four studies found significantly more asymptomatic recurrences in the intensive follow-up group ${ }^{4-7}$ and four studies found that recurrences were also detected earlier with intensive surveillance. ${ }^{2-5}$ This translated into a significantly higher rate of reoperation, with a curative intent, in two studies. ${ }^{5,7}$

There are several published meta-analyses evaluating the role of follow-up after curative resection of primary colorectal cancer. ${ }^{17-20}$ Only four of these are limited to randomized controlled data and evaluate the impact of surveillance on survival. ${ }^{10-13}$ These four metaanalyses reported a $20 \%$ to $33 \%$ reduction in the hazard ratio for all cause-mortality for those individuals who received intensive follow-up, with an absolute risk reduction of $7 \%$ for 5 -year mortality (Table 2). ${ }^{21}$ The conclusions from each meta-analysis are similar: intensive follow-up after curative resection of colorectal cancer improves overall survival; asymptomatic recurrences and reoperation for cure were more common in patients undergoing intensive follow-up; and the wide variation in the follow-up strategies used in the studies makes it impossible to infer the best combination and frequency of visits, blood tests, endoscopic procedures, and radiologic investigations from this data.

\section{CONTROVERSY AND INTERPRETATION}

The arguments both for and against various screening strategies each have validity. The opponents to colorectal cancer follow-up point out that only two of the eight clinical trials evaluating intensive versus minimal followup have demonstrated an overall 5-year survival advantage. ${ }^{5,7}$ In addition, though they acknowledge that several meta-analyses have found an overall survival advantage with an intensive surveillance strategy, they argue that given the heterogeneity of the control strategies, these trials should not be analyzed together. For example, the intensity of the intense surveillance arm in one study ${ }^{3}$ was equivalent to the "minimal" surveillance arm in other studies. ${ }^{2,5,6}$ Moreover, they call attention to the fact that the improvement in overall survival was not secondary to a decrease in cancer-related deaths because disease-specific survival was not significantly different between the two groups. The fact that significantly more surgical procedures for recurrences were performed in the intensive surveillance arm is simply because the decision to attempt salvage surgery was made by clinicians with knowledge of the study group to which the patient belonged. In these studies, the unblinded design introduces a bias that calls into question the validity of 
Table 1 Randomized Controlled Trials of Surveillance Strategies following Colorectal Cancer Resection

\begin{tabular}{|c|c|c|c|c|}
\hline Trial and Year & Recruitment & $N$ & Intervention-Experimental & Intervention-Control \\
\hline $\begin{array}{l}\text { Rodriguez et al, } \\
2006^{9} \text { (Spain) }\end{array}$ & 1997-2001 & 259 & $\begin{array}{l}\mathrm{Hx}, \mathrm{P} / \mathrm{E} \text {, blood, CEA q } \\
3 \text { months for } 5 \text { years U/S or } \\
\text { CT q } 6 \text { months for } 3 \text { years, } \\
\text { then at } 48 \text { and } 56 \text { months }\end{array}$ & $\begin{array}{l}\mathrm{Hx}, \mathrm{P} / \mathrm{E} \text {, blood, CEA q } \\
3 \text { months for } 5 \text { years }\end{array}$ \\
\hline $\begin{array}{l}\text { Secco et al, } \\
2002^{7} \text { (Italy) }\end{array}$ & 1988-1996 & 337 & $\begin{array}{l}\text { Hx, P/E, CEA q } 3 \text { months for } \\
5 \text { years U/S q } 6 \text { months for } \\
3 \text { years, then annually for } \\
2 \text { years CXR annually for } \\
5 \text { years Rigid sigmoidoscopy } \\
\text { annually for rectal cancer patients }\end{array}$ & $\begin{array}{l}\text { "minimal follow-up program } \\
\text { performed by the physician" }\end{array}$ \\
\hline Pietra et al, $1998^{5}$ (Italy) & 1987-1990 & 207 & $\begin{array}{l}\text { Hx, P/E, CEA, U/S, CXR q } \\
3 \text { months for } 2 \text { years, then q } \\
6 \text { months for } 3 \text { years then } \\
\text { annually Liver CT annually } \\
\text { Colonoscopy annually }\end{array}$ & $\begin{array}{l}\text { Hx, P/E, CEA, U/S q } 6 \text { months } \\
\text { for first year, then annually } \\
\text { CXR, CT liver, and } \\
\text { colonoscopy annually }\end{array}$ \\
\hline $\begin{array}{l}\text { Schoemaker et al, } \\
1998^{6} \text { (Australia) }\end{array}$ & 1984-1990 & 325 & $\begin{array}{l}\text { Hx, P/E, FOBT, CBC, LFTs, CEA } \\
\text { q } 3 \text { months to } 15 \text { months, } \\
\text { then q } 6 \text { months to } 5 \text { years } \\
\text { CXR, CT liver, colonoscopy } \\
\text { annually }\end{array}$ & $\begin{array}{l}\mathrm{Hx}, \mathrm{P} / \mathrm{E}, \mathrm{FOBT}, \mathrm{CBC}, \mathrm{LFTs}, \\
\text { CEA q } 3 \text { months to } 15 \text { months, } \\
\text { then q } 6 \text { months to } 5 \text { years }\end{array}$ \\
\hline $\begin{array}{l}\text { Kjeldsen et al, } \\
1997^{4} \text { (Denmark) }\end{array}$ & 1983-1994 & 597 & $\begin{array}{l}\mathrm{Hx}, \mathrm{P} / \mathrm{E}, \mathrm{DRE} \text {, gyne exam, FOBT, } \\
\text { colonoscopy, CXR CBC, ESR, } \\
\text { LFTs q } 6 \text { months for } 3 \text { years, } \\
\text { then annually for } 2 \text { years, } \\
\text { then at } 10 \text { years, } 12.5 \text { years, } \\
\text { and } 15 \text { years }\end{array}$ & $\begin{array}{l}\text { Hx, P/E, DRE, gyne exam, } \\
\text { FOBT, colonoscopy, ESR, } \\
\text { LFTs at } 5 \text { years, } 10 \text { years, } \\
\text { and } 15 \text { years. }\end{array}$ \\
\hline $\begin{array}{l}\text { Makela et al, } 1995^{2} \\
\text { (Finland) }\end{array}$ & 1988-1990 & 106 & $\begin{array}{l}\text { Hx, P/E, CBC, FOBT, CEA, CXR q } \\
3 \text { months for } 15 \text { months, then q } \\
6 \text { months until } 42 \text { months, then } \\
\text { annually to five years Flex } \\
\text { sigmoidoscopy for rectal or } \\
\text { sigmoid tumors q } 3 \text { months } \\
\text { Colonoscopy at } 3 \text { months (if not } \\
\text { done preoperatively) then annually } \\
\text { U/S liver and primary site at } \\
6 \text { months then annually }\end{array}$ & $\begin{array}{l}\mathrm{Hx}, \mathrm{P} / \mathrm{E}, \mathrm{CBC}, \mathrm{FOBT}, \mathrm{CEA}, \\
\text { CXR q } 3 \text { months for } 15 \text { months } \\
\text { then q } 6 \text { months until } \\
42 \text { months then annually to } \\
\text { five years Rigid sigmoidoscopy } \\
\text { and barium enema annually } \\
\text { for rectal or sigmoid tumors }\end{array}$ \\
\hline $\begin{array}{l}\text { Ohlsson et al, } \\
1995^{3} \text { (Sweden) }\end{array}$ & 1983-1986 & 107 & $\begin{array}{l}\text { Hx, P/E, rigid sigmoidoscopy, CEA, } \\
\text { ALP, GGT, FOBT, CXR q } 3 \text { months } \\
\text { for } 2 \text { years, then q } 6 \text { months for } \\
2 \text { years, then at year } 5 \text {. Flexible } \\
\text { sigmoidoscopy or colonoscopy } \\
\text { at } 9,21 \text {, and } 42 \text { months } \\
\text { Colonoscopy at } 3,15,30 \text { and } \\
60 \text { months CT pelvis at } 3,6,12 \text {, } \\
18,24 \text { months }\end{array}$ & $\begin{array}{l}\text { FOBT q } 3 \text { months for } 2 \text { years, } \\
\text { then annually }\end{array}$ \\
\hline
\end{tabular}

Hx, History; P/E, physical exam; CEA, carcinogenic embryonic antigen assay; CBC, complete blood count; LFTs, liver function tests and enzymes; FOBT, fecal occult blood test; ALP, alkaline phosphatase; CXR, chest radiograph; U/S, ultrasound; CT, computed tomography; gyne, gynecologic; DRE, digital rectal examination.

this finding. Finally, they question the applicability of these relatively dated clinical trials given the advances in multimodality treatment of recurrent and metastatic colorectal cancer. Six of the studies included in the meta-analysis began recruiting patients in the $1980 \mathrm{~s}^{2-7}$ long before newer and more effective chemotherapeutics and targeted agents were available and when the indications for hepatic, pulmonary, and retroperitoneal surgery for metastatic disease were strict and narrow. As a case in point, the most recent publication is the interim 
Table 2 Summary of Meta-Analysis Results

\begin{tabular}{|c|c|c|c|}
\hline Trial & $\begin{array}{l}\text { Mortality OR M-H, } \\
\text { Fixed }(95 \% \mathrm{Cl})\end{array}$ & $\begin{array}{l}\text { Recurrence OR M-H, } \\
\text { Fixed }(95 \% \mathrm{Cl})\end{array}$ & $\begin{array}{l}\text { Disease-Free Survival OR M-H, } \\
\text { Fixed }(95 \% \mathrm{Cl})\end{array}$ \\
\hline Rodriguez et al, $2006^{9}$ & $0.77(0.41,1.45)$ & $1.10(0.63,1.90)$ & N/A \\
\hline Secco et al, $2002^{7}$ & $\mathrm{~N} / \mathrm{A}$ & $0.83(0.54,1.28)$ & N/A \\
\hline Pietra et al, $1998^{5}$ & $0.51(0.2,0.92)$ & $0.78(0.45,1.34)$ & N/A \\
\hline Schoemaker et al, $1998^{6}$ & $0.65(0.40,1.05)$ & $0.78(0.50,1.23)$ & N/A \\
\hline Kjeldsen et al, $1997^{4}$ & $0.90(0.64,1.27)$ & $1.01(0.70,1.45)$ & $0.99(0.67,1.47)$ \\
\hline Makela et al, ${ }^{2} 1995$ & $0.79(0.37,1.70)$ & $1.15(0.53,2.50)$ & N/A \\
\hline Ohlsson et al, $1995^{3}$ & $0.57(0.26,1.29)$ & $0.94(0.42,2.12)$ & $0.64(0.27,1.51)$ \\
\hline Overall & $0.73(0.59,0.91)$ & $0.91(0.75,1.10)$ & $0.92(0.64,1.31)$ \\
\hline
\end{tabular}

Note: OR less than one favors more intensive surveillance. $\mathrm{M}-\mathrm{H}$, Mantel-Haenszel.

Adapted from Jeffery et al. ${ }^{11}$

analysis of 985 patients randomized to the large multicenter European study by the Gruppo Italiano di Lavoro por la Diagnosi Anticipata (GILDA), ${ }^{8}$ and it has yet to demonstrate a difference in survival between the two arms after a mean follow-up of 14 months.

Conversely, the proponents of colorectal cancer follow-up argue that the individual clinical trials lacked the power to detect a statistically significant difference in survival. As the six meta-analyses published on the topic have all concluded, there is an overall survival advantage to postoperative surveillance. They argue that although the surveillance strategies differ between studies, the follow-up for the control arm is always less intense than the follow-up for the experimental arm, indicating that there exists a continuum of improvement in survival with surveillance-some is good, but more is always better. They are not concerned with the finding that disease-specific survival was not significantly different between the two surveillance strategies because it was only reported in two trials. ${ }^{3,4}$ They instead point out that the successful reoperation rate for recurrent disease was significantly increased and the time to recurrence detection was significantly decreased, indicating that surveillance was accomplishing what it was supposed tofinding recurrent disease early so that it can be treated for a durable cure. Lastly, they emphasize that the more chemotherapeutic and surgical options that exist, the more beneficial early detection of recurrence should be because treatment will have a higher chance of success.

\section{PUBLISHED PRACTICE GUIDELINES}

There are a wide range of published practice guidelines (Table 3), including, but not limited to, guidelines from the American Society of Clinical Oncology ${ }^{21}$ (ASCO), the National Comprehensive Cancer Network ${ }^{22}$ (US), National Health Service ${ }^{23}$ (UK), the European Society of Medical Oncology ${ }^{24}$ (ESMO), and the Program in Evidence-Based Care ${ }^{12}$ (Cancer Care, Ontario, Canada). Each of these guidelines is based on a review of the literature and regional expert opinions and consensus. The guidelines focus on frequency of physician

Table 3 Published Guidelines for Colorectal Cancer Surveillance after a Curative Resection

\begin{tabular}{|c|c|c|c|c|c|}
\hline Guideline & $\begin{array}{l}\text { Clinic Visit } \\
\text { (Months) }\end{array}$ & CEA Level & Abdominal Imaging & Chest Imaging & Colonoscopy \\
\hline ASCO & $\begin{array}{l}\text { Year 1-3: q3-6 } \\
\text { Year 4-5: q6 }\end{array}$ & Year 1-3: q3 months & Year 1-3: Annually & $\begin{array}{l}\text { Year 0-3: CT } \\
\text { annually }\end{array}$ & $\begin{array}{l}\text { Perioperative, then } \\
\text { year } 3 \text {, then } \\
\text { q5 years }\end{array}$ \\
\hline $\mathrm{NCCN}$ & $\begin{array}{l}\text { Year 1-2: q3-6 } \\
\text { Year 3-5: q6 }\end{array}$ & $\begin{array}{l}\text { Year 1-2: q3-6 months } \\
\text { Year 3-5: q6 months }\end{array}$ & CT Year 1-3: Annually & Not recommended & $\begin{array}{l}\text { At I year, then as } \\
\text { indicated }\end{array}$ \\
\hline NHS & Not specified & Not recommended & $\begin{array}{l}\text { CT or Liver U/S within } \\
\text { first } 2 \text { years }\end{array}$ & Not recommended & $\begin{array}{l}\text { Within first year, } \\
\text { then as indicated }\end{array}$ \\
\hline ESMO & Not specified & $\begin{array}{l}\text { Year 1-3: q3-6 months } \\
\text { Year 4-5: q6-12 months } \\
\text { (if initially elevated) }\end{array}$ & $\begin{array}{l}\text { Liver U/S Year 1-3: } \\
\text { q6 months } \\
\text { Year 4-5: Annually CT } \\
\text { abdomen if at high risk }\end{array}$ & $\begin{array}{l}\text { Years 1-5: CT } \\
\text { annually if high } \\
\text { risk }\end{array}$ & $\begin{array}{l}\text { At } 1 \text { year, then } \\
\text { q3-5 years }\end{array}$ \\
\hline $\mathrm{CCO}$ & $\begin{array}{l}\text { Year 1-3: q6 } \\
\text { Year 4-8: q12 }\end{array}$ & At surgeon's discretion & $\begin{array}{l}\text { Liver U/S at surgeon's } \\
\text { discretion }\end{array}$ & $\begin{array}{l}\text { CXR at surgeon's } \\
\text { discretion }\end{array}$ & $\begin{array}{l}\text { At } 6 \text { months, then } \\
\text { as indicated }\end{array}$ \\
\hline
\end{tabular}

ASCO, American Society of Clinical Oncology; NCCN, National Comprehensive Cancer Network (US); NHS, National Health Service (UK); ESMO, European Society of Medical Oncology; CCO, Program in Evidence Based Care, Cancer Care Ontario (CAN); U/S, ultrasound; CT, computed tomography; CXR, chest x-ray. 
visits, serum CEA monitoring, follow-up abdominal and chest imaging and colonoscopic evaluations. Despite being based on similar evidence there are important differences between the guidelines. Areas of contention include serum CEA monitoring, which is recommended by both of the American guidelines as well as the European Society of Medical Oncology. However the Canadian guideline merely suggests considering CEA testing, where as the UK guideline does not recommend it at all based on the current evidence. Second, follow-up abdominal imaging is fairly universal, although timelines and modalities differ with some recommending liver ultrasound and others abdominal and pelvic CT scans. Furthermore, chest-imaging recommendations vary with the majority making no recommendation or recommending CT chests as clinically indicated. Lastly, all guidelines agree on a need for follow-up colonoscopy postoperatively to ensure the colon is clean of polyps. Subsequent endoscopic follow-up is less clear, with most guidelines leaving that at the discretion of the surgeon.

\section{SPECIFIC FOLLOW-UP MODALITIES}

The common sites of recurrence following resection of colorectal cancer include the liver (33\%), lung (22\%), local (15\% for colon, $35 \%$ for rectum) and regional lymph nodes (14\%), with few second or metachronous new primaries (3\%). ${ }^{25}$ As no single screening test is best suited for all sites of recurrent disease, a combination of tests has generally been studied including clinic visits, serum CEA levels, liver imaging, and colonoscopy.

\section{Office Visits}

The benefit of follow-up visits has not been well established. In the meta-analysis by Jeffrey et al, there was no survival benefit to clinic visits versus no clinic visits (one study $^{3}$ ) or more versus fewer clinic visits (two studies ${ }^{4,5}$ ). Despite the lack of evidence, most recommendations include physician visits to coordinate and discuss the results of the surveillance tests, and to reinforce healthy behaviors, such as physical activity. ${ }^{21}$ In addition, physician visits provide an opportunity to counsel patients on new developments in genetic counseling or screening of other primaries and monitoring for long-term toxicities of therapy. ${ }^{12}$ There is also limited evidence to suggest that physician visits provide psychological support and reassure patients. ${ }^{26,27}$

\section{Carcinoembryonic Antigen}

$\mathrm{CEA}$ is an oncofetal antigen that is elevated in $~ 75 \%$ of patients with a colorectal cancer recurrence. ${ }^{28}$ The sensitivity and specificity of CEA for detecting a postoperative recurrence depends on the threshold level considered abnormal. Using a CEA cutoff of $10 \mathrm{IU} / \mathrm{L}$, the sensitivity and specificity for detecting any recurrence were $44 \%$ and $90 \%$, respectively, as compared with $80 \%$ and $42 \%$, respectively, when a cutoff of $6 \mathrm{IU} / \mathrm{L}$ was used. ${ }^{29}$ CEA is most sensitive for hepatic and retroperitoneal metastases and least sensitive for local recurrences and peritoneal or pulmonary disease. ${ }^{30}$ The levels of serum CEA may rise with a median lead-time of 4.5 to 8 months prior to the development of cancer-related symptoms. ${ }^{31}$ The lead-time, combined with the sensitivity for hepatic metastases offers the main justification for following patients with serial CEA monitoring. Two of the published meta-analyses concluded that only trials using CEA testing in the intensive arm demonstrated a significant improvement in survival with follow-up. ${ }^{10,12}$ These studies also included hepatic imaging, thus confounding the results and creating ambiguity as to the benefit of CEA testing alone. An elevated serum CEA triggers a complete evaluation for recurrent disease, including chest, abdominal, and pelvic imaging and colonoscopy. In cases where no site of disease can be found, an FDG-PET scan or even a second-look laparotomy may be employed to detect the site of disease recurrence. It is important to note, however, that the false-positive rate for CEA elevation during follow-up may be as high as $16 \%,{ }^{30}$ resulting in an extensive workup to find the suspected recurrence and unnecessary anxiety for the patient. The controversy surrounding CEA testing is not centered on the ability of serial CEA to detect a resectable hepatic metastasis, resulting in an earlier hepatic resection with curative intent, but whether earlier surgery translates into a survival benefit at the population level.

\section{Liver Imaging}

The role of hepatic imaging, including abdominal CT scan or hepatic ultrasound is one of the most controversial areas of postoperative colorectal cancer surveillance. On one side of the argument, the benefit of surveillance lies in the ability to surgically resect early colorectal metastases and most frequently these occur in the liver. On the other side, the cost of adding CT scanning (and even ultrasound) to recurrence surveillance is not insignificant. ASCO justifies the recommendation to perform yearly CT scan of the abdomen for the first 3 years following surgery because all of the published metaanalyses showed a survival benefit for "liver imaging." Specifically, there appears to be significantly more surgical procedures performed for recurrence and a 25\% lower mortality for patients undergoing liver imaging compared with nonimaging strategies. ${ }^{21}$ In a follow-up study by Arriola et al of 619 patients undergoing surveillance, imaging techniques, including abdominopelvic CT and liver ultrasound, diagnosed relapse in only $19 \%$ of patients (as compared with $72 \%$ with CEA testing), but 50 to $60 \%$ of those cases were resectable 
(as compared with $32 \%$ with CEA testing). ${ }^{32}$ Another follow-up surveillance study of 530 patients by Chau et al also demonstrated that patients whose relapses were detected by symptoms had inferior survival compared with those detected by CT scan. ${ }^{33}$ As with CEA, the question of whether earlier surgery translates into a survival benefit at the population level remains. In addition, when evaluating the role of hepatic imaging in surveillance, it must be kept in mind that both the quality of CT scans and the indications for hepatic resection are continuously evolving.

\section{Colonoscopy}

The role of follow-up colonoscopies to evaluate for anastomotic recurrence and metachronous colorectal cancers is the most widely accepted surveillance modality and it is included in most published colorectal cancer surveillance guidelines (Table 3). Most of the randomized trials evaluating surveillance strategies for colorectal cancer recurrence had a median observation period of 5 years or less; therefore, no definite conclusions can be made in regard to the incidence of second bowel cancers. The evidence for the use of colonoscopy to detect metachronous colorectal cancers and polyps comes from large population-based polyp surveillance studies. ${ }^{34}$

\section{FOLLOW-UP FREQUENCY}

The incidence of recurrent disease is $\sim 50 \%$ following curative resection of primary colorectal cancer with $71 \%$ of recurrences occurring in the first 2 years following resection and $91 \%$ by 5 years. ${ }^{35}$ It is for this reason that most follow-up studies have conducted frequent tests during the first 2 to 3 years with less frequent tests for years 4 and 5 . The majority of screening strategies for recurrent colorectal cancer do not extend beyond 5 years. The incidence of a second colorectal cancer primary, however, occurs at a constant cumulative rate of 3\% every 6 years ${ }^{36}$ and, as such, screening tests must be done at regularly spaced intervals for life. The optimal time interval between clinic visits and surveillance tests is even less clear than the selection of modalities to use for surveillance.

\section{QUALITY OF LIFE ANALYSIS}

The impact of an intensive surveillance program on physical and psychological well-being of the patients, as well as the frequency of complications from the surveillance procedures or the incidence of false positive findings has not been well documented. The randomized trial by Shoemaker et $\mathrm{al}^{6}$ was the only study to report complications with follow-up testing (four complications of colonoscopy) with a rate of $0.55 \%$, a rate comparable to other series of colonoscopies. The quality of life and attitudes of patients participating in a surveillance program were evaluated in two studies. ${ }^{4,26} \mathrm{In}$ the pilot study by Stiggelbout et al, patients were reassured by regular contact with a physician and the anticipation of visits and tests caused only minimal anxiety. ${ }^{26}$ In the randomized trial by Kjeldsen et al, the subgroup of patients alive at the end of the study were mailed a quality of life questionnaire. ${ }^{37}$ Keeping in mind that all these patients were alive and most were disease free at the time of the questionnaire, there was no difference in quality of life measures between the two groups, again indicating that the inconvenience and anxiety of the extra tests was balanced by the more frequent reassurance given by their physician. The ongoing multicenter European GILDA trial has healthrelated quality of life as one of the primary endpoints and will also attempt to address quality of life issues in patients with and without disease recurrence.

\section{ECONOMIC ANALYSIS}

It is hard to deny that individual patients may derive benefit from the early detection and treatment of recurrent colorectal cancer, but what is not clear is whether populations of patients benefit from an "intense" surveillance strategy, as compared with a "minimal" one. There is a paucity of data regarding the cost-effectiveness of conventional versus intensive follow-up regimens. The data that does exist is often difficult to draw conclusions from, with most lacking comparison groups. Thus, a cost-benefit analysis between the two surveillance options cannot be determined.

Two studies currently exist that provide a cost per life year gained from intensive surveillance. The first study was based on a population from the south of France and used a Markov model to compare the effects of an intensive versus simplified follow-up strategy. ${ }^{38}$ Patients in the intensive group were followed based on the 1998 French Consensus Conference including serial physical examinations, CEA monitoring, colonoscopy every 3 years, abdominal imaging, and annual chest radiography. Patients in the simplified follow-up group underwent only some of these examinations, but not all and not as frequently. The costs of monitoring were evaluated over a period of 5 years after curative resection and then up to the seventh year. Costs were calculated using 1998 cost coefficients.

Using the Markov model the intensive surveillance group had a cost-effectiveness ratio of $3114 €$ (4235 USD) per quality adjusted life year (QALY) in favor of intensive follow-up. The largest benefit was seen in Dukes stage C patients with $1058 €$ (1439 USD) per QALY. The overall cost per year of life gained was $4000 €(5441$ USD) with the largest benefit again for Dukes stage C patients with $1654 €$ (2250 USD) per year of life gained. 
The second study, based out of the United Kingdom, was a rigorous evaluation of cost-effectiveness based on a meta-analysis of the existing randomized trials. ${ }^{15}$ The authors highlighted the heterogeneity of the existing randomized trials with no single method for standard or intensive follow-up. Furthermore, despite a demonstrated benefit in effectiveness and cost per life year gained, it is not possible to determine which of the specific strategies are beneficial or cost effective. However, based on 2002 cost coefficients, an intensive surveillance program provided 0.73 life years gained at a cost of $2479 £$ ( 3758 USD) per patient, or $3402 £$ (5156 USD) per life year gained.

Thus, based on these two studies it appears that a more thorough follow- up program may be cost-effective with a relatively inexpensive cost of $\sim 5000$ USD per life year gained. However, it is important to point out that it is not clear which strategies are the truly cost effective ones and what is the quality of the additional time gained. Two studies are currently in progress with secondary outcomes of cost per life year gained and quality of life. The first is the GILDA study and the second, the Follow up after Colorectal Surgery (FACS) trial based out of the UK, which opened in 2004. More studies are needed to determine the cost-effectiveness in other countries and specifically in North America where the health care system and costs are different than those of Europe and the UK.

\section{COMPLIANCE WITH CURRENT GUIDELINES}

Several studies have evaluated the compliance with various colorectal cancer surveillance guidelines. ${ }^{39-42}$ The adherence to surveillance guidelines is generally low with only $7 \%$ of patients receiving minimum predefined CEA follow-up in one retrospective study. ${ }^{39}$ Several barriers to surveillance have been identified by health care providers including unclear guidelines and confusion as to which provider is in charge of ordering investigations. ${ }^{43}$ Indeed, the creation of a dedicated colorectal cancer follow-up clinic demonstrated improved compliance with postoperative surveillance in one study. ${ }^{44}$ Interestingly, patient compliance with follow-up regimens, evaluated in three trials, was quite good indicating that patients are willing to accept frequent visits and testing.

\section{FOLLOW-UP STUDIES IN PROGRESS}

As previously mentioned, there are several studies evaluating surveillance strategies in patients with resected colorectal cancer that are still in progress. The GILDA group of investigators in Italy is currently conducting a randomized trial of follow-up in patients with Dukes B or C colorectal cancer. The trial opened in 1998 and has a target accrual of 1500 patients, making it the largest trial to date. In designing this trial, it was felt that CEA was already so deeply rooted in practice that exclusion from a postoperative program was deemed unfeasible. The "intensive" arm was instead designed to assess the potential of other diagnostic tests, such as chest x-ray (CXR), liver imaging, and more frequent colonoscopies on overall and disease-specific survival. Health-related quality of life is also a primary endpoint in this study. An interim analysis of 985 patients, published in 2004, did not demonstrate any improvement in overall survival between the two surveillance arms, but the follow-up time was short. The FACS trial from the UK opened in 2004 with a target recruitment of 4,890 patients who have undergone curative treatment for primary colorectal cancer (Dukes A-C). The study compares primary care to intensive hospital follow-up with CT and ultrasound scanning. The primary objective is the number of recurrences treated surgically with curative intent with overall survival as a secondary endpoint. Several reports suggest that enrollment is slow. ${ }^{11,45}$ The COLOFOL study includes patients with a resected Dukes B or C colorectal cancer randomized to a low or high frequency follow-up regimen that includes serum $\mathrm{CEA}, \mathrm{CT}$, or magnetic resonance imaging (MRI) of the liver, and CXR or CT of the lungs. The only difference between the regimens is the interval between follow-up testing, which is performed at 1 and 3 years for the low frequency cohort and at 6 month intervals in the high frequency cohort. The primary outcomes are overall and disease-specific survival at 5 years. These studies are unlikely to clarify the role of serum CEA monitoring in colorectal cancer surveillance because the control arms in each study include it, albeit at a reduced frequency. These studies will primarily address the use of additional imaging modalities and the frequency of follow-up testing in an era of more aggressive hepatic surgery and more effective chemotherapeutics to treat colorectal cancer recurrences.

\section{NEWER SURVEILLANCE STRATEGIES}

${ }^{18}$ FDG-PET has emerged as a promising diagnostic imaging modality in evaluating recurrent colorectal cancer. It has been used to help select patients for hepatic resection ${ }^{46,47}$ and to evaluate patients with an elevated CEA and normal conventional imaging and colonoscopy. ${ }^{48,49}$ The use of systematic ${ }^{18}$ FDG-PET as part of a surveillance strategy to detect tumor recurrence has been assessed in one randomized trial. In this study, 130 patients were randomized to conventional follow-up (including a clinic visit, CEA, and liver ultrasound every 3 months, a CXR every 6 months and an abdominal CT scan at 9 and 15 months), or conventional follow-up plus an ${ }^{18}$ FDG-PET scan at 9 and 15 months. The results demonstrated that the time from baseline to recurrence was significantly shorter in the PET group 
and recurrences were also more frequently cured by surgery (R0 resection). Of the 65 patients screened with PET scan, three had false-positive findings and three had an unrelated primary detected (two lung cancers and one gastrointestinal stromal tumor). Although these results are interesting, the current cost of PET makes wide application of this strategy unlikely at the present time.

\section{CONCLUSION}

Though it appears that surveillance following colorectal cancer resection is beneficial in terms of earlier detection of recurrence, resulting in more surgical resections with curative intent, there is only limited evidence to suggest that overall survival is improved. Which modalities are most valuable and what is the optimal frequency of follow-up is less clear. Physician visits, whether they are used to provide reassurance and encourage a health lifestyle or to coordinate follow-up studies, are a mainstay of colorectal surveillance strategies. Furthermore, colonoscopic evaluation to ensure the absence of anastomotic recurrence or metachronous disease is essential. Areas of contention include serum CEA monitoring and chest imaging, as well as the type and frequency of liver imaging. Future considerations are the cost-effectiveness of various surveillance strategies, the quality of life implications and the role of different surveillance techniques in light of recent improvements and advances in chemotherapeutics and the surgical management of metastatic disease.

\section{REFERENCES}

1. Böhm B, Schwenk W, Hucke HP, Stock W. Does methodic long-term follow-up affect survival after curative resection of colorectal carcinoma? Dis Colon Rectum 1993;36(3):280286

2. Mäkelä JT, Laitinen SO, Kairaluoma MI. Five-year followup after radical surgery for colorectal cancer. Results of a prospective randomized trial. Arch Surg 1995;130(10):10621067

3. Ohlsson B, Breland U, Ekberg H, Graffner H, Tranberg KG. Follow-up after curative surgery for colorectal carcinoma. Randomized comparison with no follow-up. Dis Colon Rectum 1995;38(6):619-626

4. Kjeldsen BJ, Kronborg O, Fenger C, Jørgensen OD. A prospective randomized study of follow-up after radical surgery for colorectal cancer. Br J Surg 1997;84(5): 666-669

5. Pietra N, Sarli L, Costi R, Ouchemi C, Grattarola M, Peracchia A. Role of follow-up in management of local recurrences of colorectal cancer: a prospective, randomized study. Dis Colon Rectum 1998;41(9):1127-1133

6. Schoemaker D, Black R, Giles L, Toouli J. Yearly colonoscopy, liver CT, and chest radiography do not influence 5-year survival of colorectal cancer patients. Gastroenterology 1998;114(1):7-14
7. Secco GB, Fardelli R, Gianquinto D, et al. Efficacy and cost of risk-adapted follow-up in patients after colorectal cancer surgery: a prospective, randomized and controlled trial. Eur J Surg Oncol 2002;28(4):418-423

8. Grossmann EM, Johnson FE, Virgo KS, Longo WE, Fossati R. Follow-up of colorectal cancer patients after resection with curative intent-the GILDA trial. Surg Oncol 2004;13 (2-3):119-124

9. Rodríguez-Moranta F, Saló J, Arcusa A, et al. Postoperative surveillance in patients with colorectal cancer who have undergone curative resection: a prospective, multicenter, randomized, controlled trial. J Clin Oncol 2006;24(3): 386-393

10. Tjandra JJ, Chan MK. Follow-up after curative resection of colorectal cancer: a meta-analysis. Dis Colon Rectum 2007;50(11):1783-1799

11. Jeffery M, Hickey BE, Hider PN. Follow-up strategies for patients treated for non-metastatic colorectal cancer. Cochrane Database Syst Rev 2007;(1):CD002200

12. Figueredo A, Rumble RB, Maroun J, et al; Gastrointestinal Cancer Disease Site Group of Cancer Care Ontario's Program in Evidence-based Care. Follow-up of patients with curatively resected colorectal cancer: a practice guideline. BMC Cancer 2003;3:26

13. Renehan AG, Egger M, Saunders MP, O'Dwyer ST. Impact on survival of intensive follow up after curative resection for colorectal cancer: systematic review and meta-analysis of randomised trials. BMJ 2002;324(7341):813

14. Renehan AG, Egger M, Saunders MP, O’Dwyer ST. Mechanisms of improved survival from intensive followup in colorectal cancer: a hypothesis. Br J Cancer 2005;92(3): 430-433

15. Renehan AG, O'Dwyer ST, Whynes DK. Cost effectiveness analysis of intensive versus conventional follow up after curative resection for colorectal cancer. BMJ 2004; 328(7431):81

16. Goldberg RM, Fleming TR, Tangen CM, et al. Surgery for recurrent colon cancer: strategies for identifying resectable recurrence and success rates after resection. Eastern Cooperative Oncology Group, the North Central Cancer Treatment Group, and the Southwest Oncology Group. Ann Intern Med 1998;129(1):27-35

17. Bruinvels DJ, Stiggelbout AM, Kievit J, van Houwelingen HC, Habbema JD, van de Velde CJ. Follow-up of patients with colorectal cancer. A meta-analysis. Ann Surg 1994; 219(2):174-182

18. Rosen M, Chan L, Beart RW Jr, Vukasin P, Anthone G. Follow-up of colorectal cancer: a meta-analysis. Dis Colon Rectum 1998;41(9):1116-1126

19. Audisio RA, Robertson C. Colorectal cancer follow-up: perspectives for future studies. Eur J Surg Oncol 2000;26(4): 329-337

20. Edelman MJ, Meyers FJ, Siegel D. The utility of follow-up testing after curative cancer therapy. A critical review and economic analysis. J Gen Intern Med 1997;12(5):318-331

21. Desch CE, Benson AB III, Somerfield MR, et al; American Society of Clinical Oncology. Colorectal cancer surveillance: 2005 update of an American Society of Clinical Oncology practice guideline. J Clin Oncol 2005;23(33):8512-8519

22. Practice NCCN. Guidelines in Oncology. National Comprehensive Cancer Network, 2009. Available at: http:// www.nccn.org/professionals/physician_gls/f_guidelines.asp. Accessed June 5, 2009 
23. Scholefield JH, Steele RJ; British Society For GastroenterologyAssociation of Coloproctology for Great Britain and Ireland. Guidelines for follow up after resection of colorectal cancer. Gut 2002;51(Suppl 5):V3-V5

24. Van Cutsem EJ, Oliveira J; ESMO Guidelines Working Group. Colon cancer: ESMO clinical recommendations for diagnosis, adjuvant treatment and follow-up. Ann Oncol 2008;19(Suppl 2):ii29-ii30

25. Galandiuk S, Wieand HS, Moertel CG, et al. Patterns of recurrence after curative resection of carcinoma of the colon and rectum. Surg Gynecol Obstet 1992;174(1):27-32

26. Stiggelbout AM, de Haes JC, Vree R, et al. Follow-up of colorectal cancer patients: quality of life and attitudes towards follow-up. Br J Cancer 1997;75(6):914-920

27. Kiebert GM, Welvaart K, Kievit J. Psychological effects of routine follow up on cancer patients after surgery. Eur J Surg 1993;159(11-12):601-607

28. Mayer RJ, Garnick MB, Steele GD Jr, Zamcheck N. Carcinoembryonic antigen (CEA) as a monitor of chemotherapy in disseminated colorectal cancer. Cancer 1978;42(3, Suppl):1428-1433

29. Glover C, Douse P, Kane P, et al. Accuracy of investigations for asymptomatic colorectal liver metastases. Dis Colon Rectum 2002;45(4):476-484

30. Moertel CG, Fleming TR, Macdonald JS, Haller DG, Laurie JA, Tangen C. An evaluation of the carcinoembryonic antigen (CEA) test for monitoring patients with resected colon cancer. JAMA 1993;270(8):943-947

31. Goldstein MJ, Mitchell EP. Carcinoembryonic antigen in the staging and follow-up of patients with colorectal cancer. Cancer Invest 2005;23(4):338-351

32. Arriola E, Navarro M, Parés D, et al. Imaging techniques contribute to increased surgical rescue of relapse in the followup of colorectal cancer. Dis Colon Rectum 2006;49(4):478484

33. Chau I, Allen MJ, Cunningham D, et al. The value of routine serum carcino-embryonic antigen measurement and computed tomography in the surveillance of patients after adjuvant chemotherapy for colorectal cancer. J Clin Oncol 2004;22(8):1420-1429

34. Winawer SJ, Zauber AG, O'Brien MJ, et al; The National Polyp Study Workgroup. Randomized comparison of surveillance intervals after colonoscopic removal of newly diagnosed adenomatous polyps. N Engl J Med 1993;328(13): 901-906

35. Griffin MR, Bergstralh EJ, Coffey RJ, Beart RW Jr, Melton LJ III. Predictors of survival after curative resection of carcinoma of the colon and rectum. Cancer 1987;60(9):23182324

36. Enblad P, Adami HO, Glimelius B, Krusemo U, Påhlman L. The risk of subsequent primary malignant diseases after cancers of the colon and rectum. A nationwide cohort study. Cancer 1990;65(9):2091-2100
37. Kjeldsen BJ, Thorsen H, Whalley D, Kronborg O. Influence of follow-up on health-related quality of life after radical surgery for colorectal cancer. Scand J Gastroenterol 1999; 34(5):509-515

38. Borie F, Combescure C, Daurès JP, Trétarre B, Millat B. Cost-effectiveness of two follow-up strategies for curative resection of colorectal cancer: comparative study using a Markov model. World J Surg 2004;28(6):563-569

39. Spratlin JL, Hui D, Hanson J, Butts C, Au HJ. Community compliance with carcinoembryonic antigen: follow-up of patients with colorectal cancer. Clin Colorectal Cancer 2008;7(2):118-125

40. Cheung WY, Pond GR, Rother M, et al. Adherence to surveillance guidelines after curative resection for stage II/III colorectal cancer. Clin Colorectal Cancer 2008;7(3):191-196

41. Grossmann I, de Bock GH, van de Velde CJ, Kievit J, Wiggers T. Results of a national survey among Dutch surgeons treating patients with colorectal carcinoma. Current opinion about follow-up, treatment of metastasis, and reasons to revise follow-up practice. Colorectal Dis 2007;9(9): 787-792

42. Giordano P, Efron J, Vernava AM III, Weiss EG, Nogueras JJ, Wexner SD. Strategies of follow-up for colorectal cancer: a survey of the American Society of Colon and Rectal Surgeons. Tech Coloproctol 2006;10(3):199-207

43. Cardella J, Coburn NG, Gagliardi A, et al. Compliance, attitudes and barriers to post-operative colorectal cancer follow-up. J Eval Clin Pract 2008;14(3):407-415

44. Cheah LP, Hemingway DM. Improving colorectal cancer follow-up: the dedicated single-visit colorectal cancer followup clinic. Ann R Coll Surg Engl 2002;84(4):260-262

45. Renehan AG, Wille-Jørgensen P. Towards a more prescriptive follow-up regimen for colorectal cancer. Colorectal Dis 2006;8(8):623-625

46. Fernandez FG, Drebin JA, Linehan DC, Dehdashti F, Siegel BA, Strasberg SM. Five-year survival after resection of hepatic metastases from colorectal cancer in patients screened by positron emission tomography with $\mathrm{F}-18$ fluorodeoxyglucose (FDG-PET). Ann Surg 2004;240(3):438-447; discussion $447-450$

47. Fong Y, Saldinger PF, Akhurst T, et al. Utility of $18 \mathrm{~F}-\mathrm{FDG}$ positron emission tomography scanning on selection of patients for resection of hepatic colorectal metastases. Am J Surg 1999;178(4):282-287

48. Shen YY, Liang JA, Chen YK, Tsai CY, Kao CH. Clinical impact of 18F-FDG-PET in the suspicion of recurrent colorectal cancer based on asymptomatically elevated serum level of carcinoembryonic antigen (CEA) in Taiwan. Hepatogastroenterology 2006;53(69):348-350

49. Flanagan FL, Dehdashti F, Ogunbiyi OA, Kodner IJ, Siegel BA. Utility of FDG-PET for investigating unexplained plasma CEA elevation in patients with colorectal cancer. Ann Surg 1998;227(3):319-323 